\title{
Physical Health Hazards of Mobile Phone Use
}

\section{Motuma Adimasu Abeshu ${ }^{1 *}$ and Bekesho Geleta ${ }^{2}$}

${ }^{1} J o h n$ Snow, Inc (JSI)-Ethiopia, Addis Ababa, Ethiopia

${ }^{2}$ Ethiopian Public Health Institute, Addis Ababa, Ethiopia

\begin{abstract}
Mobile phones communicate with base stations using radiofrequency radiation. Radio waves received and sent by mobile phones transmit in all directions including the human body. An exposure to the radiofrequency fields emitted by mobile phones is generally more than a 1000 time s higher than from base stations. This radiation is absorbed into body might cause a wide range of health problems. If radiofrequency radiation is high enough, it has a 'thermal' effect, which means it raises body temperature. There are concerns that the low levels of radiofrequency radiation emitted by mobile phones could cause health problems.
\end{abstract}

Keywords: Mobile phone; Thermal effects; Health problems; Radiofrequency

\section{Introduction}

Mobile (cellular) telephony is based on two-way radio communication between a portable handset and the nearest basestation. As the user of a mobile phone moves from cell to cell, the call is transferred between base-stations without interruption. The radio communication utilizes microwaves at 900 or $1800 \mathrm{MHz}$ to carry voice information $[1,2]$.

Despite their introduction during the late 1990s, there is an estimated 5 billion subscriptions worldwide at mid-2010, only from 500 million users in 2000 [3,4]. This is followed by increased concerns of possible interactions of electromagnetic radiation with the human body.

Until now, no conclusive scientific evidence regarding the health effects of mobile phones has been forwarded. As time goes by, some health risks from short term and prolonged use are reported. These risks range from self-reported problems such as headache, difficulties in concentration, dizziness, depressive symptoms, sleep disturbances, to radiation and oxidative stress, effect on DNA strands, effect on male reproductive system, effect on membrane structure and function, and carcinogenesis.

Therefore, the objective of this paper is to review the health risks of mobile phone over short and long term uses.

\section{Method}

Peer reviewed articles were consulted using PubMed Central, Bioline International, doaj, Genesis Library, and Google scientific. Studies on health risk of mobile phone use were selected from the search results, potentially eligible articles were identified. Using the title of the study as primary criteria, proper articles were shortlisted followed by review of the abstracts. Finally, the entire article was examined for review. Key and free-text words included were 'mobile phone', 'cellular phone, 'health risk of mobile phone, 'radiation from mobile phone and health risk'.

\section{Results and Discussion}

Various researches suggest that the thermal and non-thermal effects of electromagnetic radiation as a possible mechanism implicated in the health risks of mobile telephone use [1].

\section{Thermal effects}

Mobile phones transmit and receive waves of frequencies mainly at $800-1800 \mathrm{MHz}$. Findings on the thermal effect of acute exposure to radiofrequency fields were consistent. Radiations from mobile phones during communication rise body temperature by as much as $0.1^{\circ} \mathrm{C}$. This rise in cellular, tissue or body temperature is found to have effect on the body [2,5-7].

\section{Non-thermal effects}

Animal studies show that acute exposure to radiofrequencies from mobile phones may induce a rise in body temperature of as $1^{\circ} \mathrm{C}$ which may provoke variety of behavioral and physiological disorders. In thermally vulnerable areas of the body such as eyes and testes, cataract formation and reduced sperm counts are well-documented acute exposure hazards [1].

\section{In vitro studies}

The mechanism employed in non-thermal effect of mobile phone use is yet unclear. Animal studies regarding the impact of mobile phones on the body present mixed findings. In rats, evidence for neuronal damage in the cortex, hippocampus, and basal ganglia up on exposure to Global System for Mobile Communications (GSM) for $2 \mathrm{hrs}$ was documented [8]. In the contrary, no change in brain parameters of rabbits was seen. However, significant elevation of the activity of superoxide dismutase (SOD), and reduction in the levels of Nitric Oxide (NO) in the sera of EMR-exposed rabbits were observed that may play pathophysiological role due to oxidative stress in vascular structures of rabbits [9].

Exposure of Jukart T-cells, fibroblast and mononuclear cells of immune system to electromagnetic radiations over 8 hours resulted in increased protein synthesis, where, metabolically active and/or proliferating cells are more responsive thus increasing the concern that there is higher sensitivity in growing organisms [5].

Radiations from mobile phones are assumed to alter membrane

*Corresponding author: Motuma Adimasu Abeshu, John Snow, Inc (JSI)Ethiopia, P.O Box 27236, Addis Ababa, Ethiopia, Vaccine Supply Chain Advisor Tel: 251 921462246; E-mail: motumad4@gmail.com

Received December 22, 2015; Accepted December 25, 2015; Published December 31, 2015

Citation: Abeshu MA, Geleta B (2015) Physical Health Hazards of Mobile Phone Use. Health Care Current Reviews 3: 153. doi: 10.4172/2375-4273.1000153

Copyright: (c) 2015 Abeshu MA, et al. This is an open-access article distributed under the terms of the Creative Commons Attribution License, which permits unrestricted use, distribution, and reproduction in any medium, provided the original author and source are credited. 
structural and functional properties and trigger cellular responses. But, at high frequencies, such low-level RF fields do not induce appreciable membrane potentials. Rather, they can penetrate the cell membrane and possibly influence cytoplasmic structure and function [10]. However, no conclusive evidence is available to prove exposure at power and frequencies related to mobile communication could interfere with the functional and structural integrity of the brain [11].

Radio frequency-electromagnetic waves of 869 to $894 \mathrm{MHz}$ were shown to decrease the size of the testicular organs, presumably the seminiferous tubules and epithelium thickness, by changing the blood-testis barrier [12]. In addition, exposure at $900 \mathrm{MHz}$ caused subtle decrease in the rapid progressive and slow progressive sperm movement [13]

\section{Human studies}

Several studies suggest that there are self-reported non-specific symptoms of mobile telephone uses. These symptoms include headache, cold hands or feet, difficulties in concentration, memory changes, dizziness, depressive symptoms, sleep disturbances $[10,14,15]$.

Analysis conducted by Levis et al. [3] suggests that most studies conducted to uncover the health risk of mobile telephones were subject to methodological fallacy. It points out that blind protocols gave positive results suggesting a cause-effect relationship between longterm mobile phone use and increase of ipsilateral head tumor risk. The non-blind protocols, however, gave negative results with systematic underestimation of such risks [3].

Population based retrospective cohort study conducted in Denmark on all users of cellular telephones during the period of 1982 to 1995 concluded that there exists no association between the use of mobile telephones and tumors of the brain or salivary gland, leukemia, or other cancers. According to this study, neither the duration of cellular telephone use, time since first subscription, age at first subscription, nor the type of cellular telephone used affects the risk for these cancers $[2,15,16]$. When the temperature is maintained within physiological limits and thermal effect is not involved, RF radiation cannot initiate tumor formation, enhance the effects of known carcinogens or promote the growth of transplanted tumors [10].

\section{Conclusion}

Mobile phones emit radiations between 900 to $1800 \mathrm{MHz}$. Since their introduction in late 1990s, about 6.8 billion people worldwide are currently using mobile phones. Through time speculation and concern of possible health risks of use of mobile phones increased. However, existing scientific findings are inconsistent. Several studies indicate self-reported symptoms such as headache, migraine, difficulties in concentration, memory changes, dizziness, depressive symptoms, sleep disturbances associated with/following to long time exposure per day over longer period of time. However, no conclusive evidence has been found to support the concern that mobile phone use is implicated with initiating or enhancing the course of carcinogenesis.

\section{Recommendation}

Based on review of available literature, the following cautions/ recommendations are suggested:

a. Shortening the duration of use of mobile phones per day may reduce any risk associated with exposure to radiations from mobile phones. Therefore, it is highly recommended to limit the duration of conversation on mobile phones. b. Since in vitro studies suggest that mobile phones may have thermal effect on sensitive parts of the body, such as, eyes and testis, it is recommended to minimize exposure to such body parts to be on safe side.

c. Another in vitro study, also, suggests that growing and highly proliferating cells are much more prone to the effect of mobile phones. Therefore, it is recommended to keep children from getting exposed to radiations of mobile phones.

d. Furthermore, more researches are required to address the conflicting reports of health risks from mobile telephone use, and to set clear guideline regarding the exposure thresholds permissible to radiations from mobile phones.

\section{References}

1. Hyland GJ (2000) Physics and biology of mobile telephony. Lancet 356: 1833 1836.

2. Johansen C, Boice JD, McLaughlin JK, Olsen JH (2001) Cellular Telephones and Cancer-a Nationwide Cohort Study in Denmark. Journal of the National Cancer Institute 93: 203-207

3. Levis AG, Minicuci N, Ricci P, Gennaro V, Garbisa S (2011) Mobile phones and head tumours. The discrepancies in cause-effect relationships in the epidemiological studies - how do they arise? Environmental Health 10: 1-15.

4. Samkange-Zeeb F, Blettner M (2009) Emerging aspects of mobile phone use Emerging Health Threats Journal 2: 1-8.

5. Gerner C, Haudek V, SchandI U, Bayer E, Gundacker N et al. (2010) Increased protein synthesis by cells exposed to a $1,800-\mathrm{MHz}$ radio-frequency mobile phone electromagnetic field, detected by proteome profiling. Int Arch Occup Environ Health: 691-702.

6. Blettner M, Berg G (2000) Are Mobile Phones Harmful? Acta Oncologica 39 927-930

7. Maier M, Blakemore C, Koivisto M (2000) British Medical Journal 320: 1288 1289.

8. Salford LG, Brun AE, Eberhardt JL, Malmgren J, Persson BRR (2003) Nerve Cell Damage in Mammalian Brain after Exposure to Microwaves from GSM Mobile Phones. Environmental Health Perspectives 111: 881-883

9. Irmak MK, Fadillioglu E, Gulec M, Erdogan H, Yagmurca M, et al. (2002) Effects of electromagnetic radiation from a cellular telephone on the oxidant and antioxidant levels in rabbits. Cell Biochem Funct 20: 279-283.

10. Repacholi MH (2001) Health risks from the use of mobile phones. Toxicology Letters 120: 323-331.

11. Hossmann KA, Hermann DM (2003) Effects of Electromagnetic Radiation of Mobile Phones on the Central Nervous System. Bioelectromagnetics 24: 49-62.

12. Desai NR, Kesari KK, Agarwal A (2009) Pathophysiology of cell phone radiation: oxidative stress and carcinogenesis with focus on male reproductive system. Reproductive Biology and Endocrinology 7:114.

13. Erogul O, Oztas E, Yildirim I, Kir T, Aydur E et al. (2006) Effects of Electromagnetic Radiation from a Cellular Phone on Human Sperm Motility: An In Vitro Study. Archives of Medical Research 37: 840-843.

14. Röösli M, Frei P, Mohler P, Hug K (2010) Systematic review on the health effects of exposure to radiofrequency electromagnetic fields from mobile phone base stations. Bull World Health Organ 88: 887-896.

15. Schu z J, Waldemar G, Olsen JH, Johansen C (2009) Risks for Central Nervous System Diseases among Mobile Phone Subscribers: A Danish Retrospective Cohort Study. PLoS ONE 4: e4389.

16. Cooke R, Laing S, Swerdlow AJ (2010) A case-control study of risk of leukemia in relation to mobile phone use. British Journal of Cancer 103: 1729-1735. 